\title{
ArcheoSciences
}

Revue d'archéométrie

33 (suppl.) | 2009

Mémoire du sol, espace des hommes

\section{What interest to use caesium magnetometer instead of fluxgate gradiometer?}

Vivien Mathé, François Lévêque and Marion Druez

\section{OpenEdition}

1 Journals

Electronic version

URL: https://journals.openedition.org/archeosciences/1781

DOI: 10.4000/archeosciences. 1781

ISBN: 978-2-7535-1599-4

ISSN: 2104-3728

Publisher

Presses universitaires de Rennes

Printed version

Date of publication: 30 October 2009

Number of pages: $325-327$

ISBN: 978-2-7535-0943-6

ISSN: 1960-1360

\section{Electronic reference}

Vivien Mathé, François Lévêque and Marion Druez, "What interest to use caesium magnetometer instead of fluxgate gradiometer?", ArcheoSciences [Online], 33 (suppl.) | 2009, Online since 30 October 2011, connection on 21 September 2021. URL: http://journals.openedition.org/archeosciences/1781 DOI: https://doi.org/10.4000/archeosciences. 1781 


\title{
What interest to use caesium magnetometer instead of fluxgate gradiometer?
}

\author{
Vivien Mathé*, François LÉvÊque ${ }^{* *}$ and Marion Druez ${ }^{* * *}$
}

Key words: Caesium magnetometer, Fluxgate gradiometer, Total magnetic field, Vertical pseudogradient, Vertical gradient.

Magnetic prospecting is increasingly used to map archaeological remains. Indeed, this method has its interest compared to other approaches, such as electrical resistivity method. Independent of the soil water content, it combines speed with high spatial resolution. Moreover, the sensors developed over the last fifteen years are sensitive to minimal changes in the magnetic signal. They rely on instrumental principles that can be very different. Caesium magnetometers and fluxgate gradiometers are currently the magnetic prospecting instruments used most often to perform archaeological research.

In this study, the results of a Geometrics G858 magnetometer with two caesium sensors have been compared with those of a Foerster FEREX 4.032 gradiometer with four fluxgate sensors. The signal measured by each instrument is different. Each caesium sensor measure the intensity of the total magnetic field which depends on the soil-sensor distance. A common configuration consists of two sensors positioned one above the other. The difference between signals measured by each sensor (in this study: $0.3 \mathrm{~m}$ high signal minus $1.2 \mathrm{~m}$ high signal), called the pseudogradient, allows the temporal variations of the total field to be removed. The fluxgate sensors measure the gradient of the vertical component of the magnetic field between two points spaced at $0.65 \mathrm{~m}$. Consequently, the FEREX gives only a single value per profile while the G858 provides three (total field at two heights and pseudogradient). In addition, the sensitivity of FEREX is lower: $0.3 \mathrm{nT}$ (depending on the manufacturer) against $0.1 \mathrm{nT}$ for the G858 (Mathé et al., 2006). This implies a lower detection ability for the FEREX (Linford et al., 2007).

Based on this observation, we tested both systems on several sites with a variety of archaeological structures (ovens, fireplaces, pools, ditches, stone walls). A caesium sensor located close to the soil, i. e., close to the magnetic sources, detects the most informative signal from not only superficial but also deeper sources (Fig. 1). The sensor that is used as reference to remove the temporal variations is sensitive to the deeper structures, i.e., the sources of plurimetric anomalies. It is not placed high enough $(1.2 \mathrm{~m})$ not to be disturbed by part of the soil signal (Mathé et al., 2006). The pseudogradient is therefore less intense than the anomaly measured close to ground level. In some cases, this may result in loss of information. This corresponds also to a filtering of anomalies which have greater spatial extension (Fig. 1B). The pseudogradient then reveals details not easily visible on the map of total field variations. In this case, the FEREX gradiometer produces a high performance. Its four sensors can not only reduce the acquisition time, but also double the spatial resolution. And this parameter is decisive for the interpretation of the magnetic signal (Mathé and Lévêque, 2003).

On a site prospected with the two instruments for the same spatial resolution (Fig. 2), the quality of information collected depends on the nature and location of magnetic

* UMR6250 LIENSs University of La Rochelle-CNRS. (vmathe@univ-lr.fr)

** UMR6250 LIENSs University of La Rochelle-CNRS. (fleveque@univ-lr.fr)

***ULRValor. (mdruez@univ-lr.fr) 


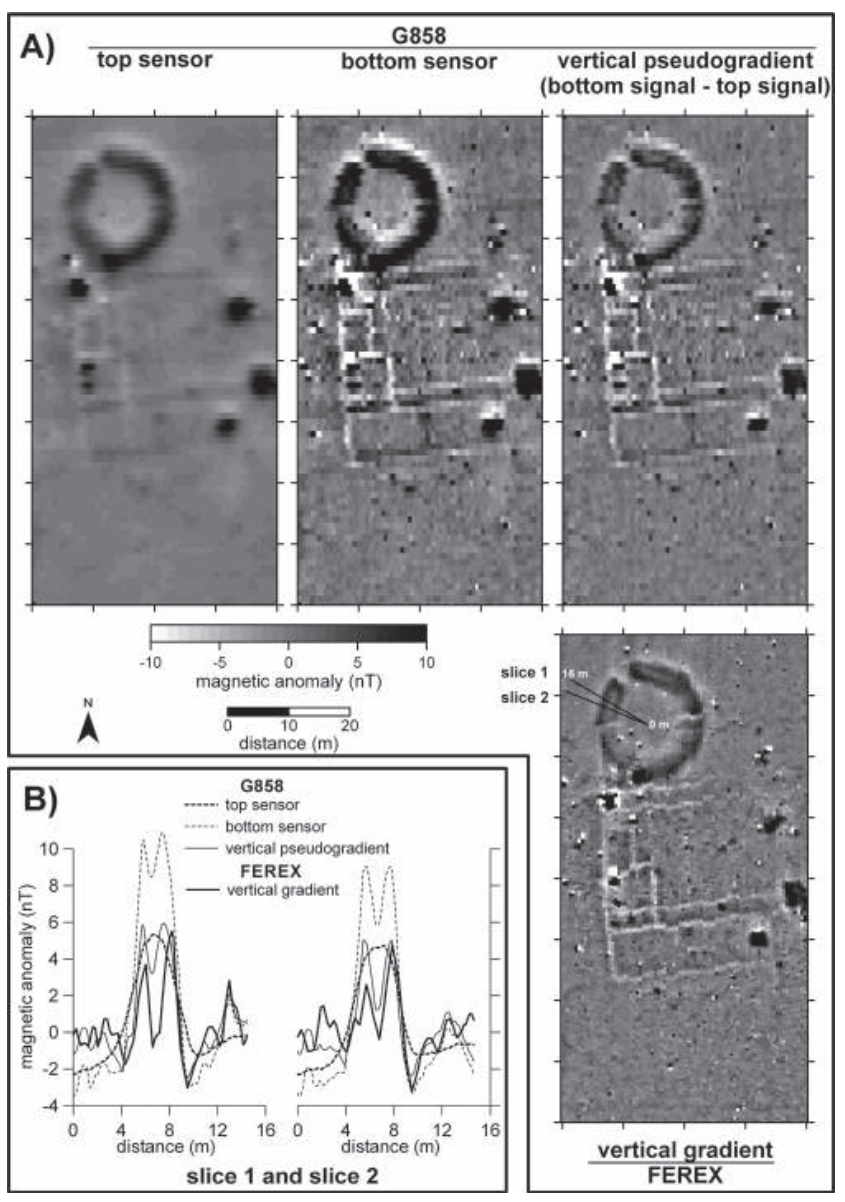

Figure 1: Magnetic survey of a Gallo-Roman villa. A) Maps of magnetic anomalies. The presented values are the differences in the median of each profile. G858 magnetometer: bottom sensor is at $0.3 \mathrm{~m}$, top at $1.2 \mathrm{~m}$ above soil surface; 10 measurements per $\mathrm{m}^{2}$. FEREX gradiometer: each sensor, $0.3 \mathrm{~m}$ above soil surface, $0.65 \mathrm{~m}$ length; 20 measurements per $\mathrm{m}^{2}$. B) Slices 1 and 2 . Total field measured near the soil surface shows the highest dynamics (metric and decimetric variations). Vertical gradient is here the best method to underline the decimetric anomalies which are not detected by the top sensor (only metric variations).

sources. When several ovens are close together, they create intense anomalies which are combined. These anomalies are more easily identified in the pseudogradient or the vertical gradient signal than in the total field. On the other hand, unlike the caesium sensor located near the surface, these devices will not detect large and weak anomalies (structures oriented NW-SE). This is especially true because of the lower sensitivity of fluxgate gradiometers (Linford et al., 2007). A total field sensor is more suitable for mapping archaeological structures significantly disturbing the field but with low gradients. In this case, gradiometers can identify most often only the structure limits (for example, only the edges of a wide ancient road are detected).

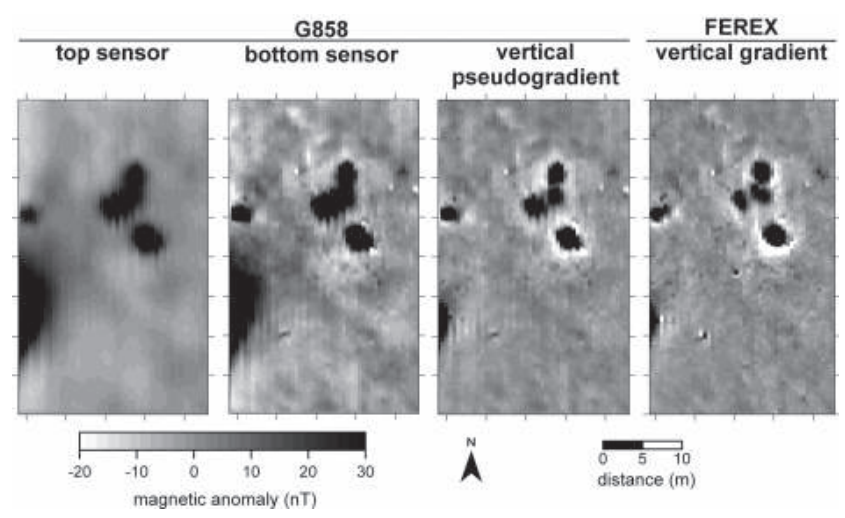

Figure 2: Magnetic survey of a production site of Gallo-Roman ceramics. Spatial resolution of each map is 20 measurements per $\mathrm{m}^{2}$. These results are obtained after removal of the median of each profile and pole reduction. The pseudogradient and the vertical gradient show only ovens, while the variations of the total field at $0.3 \mathrm{~m}$ height exhibit associated structures.

The gradient of the field is also less informative than the field itself on sites with many intense and small magnetic sources. This is, for example, the case of a brick-production site (Fig. 3). Multiple fragments of bricks, bearing thermoremanent magnetization and scattered on the soil surface, are the cause of a strong spatial variation of the magnetic signal (high frequency noise). They make it difficult to identify archaeological structures with the exception of ovens. Most of the signal in this case is constituted by elements which are not in place, thus of lesser interest. The total field, even measured at $1.2 \mathrm{~m}$ above the soil, is much more efficient here. Indeed, it is the magnetization of non-displaced structures, mainly induced magnetization (except for ovens) that constitutes the largest part of the signal. It should be noted that the further from the soil that the field is measured, the lesser the disturbance due to bricks because the orientation of thermoremanent magnetizations is random.

Finally, the total field appears to be the more informative measurement. Of course, the FEREX gradiometer is useful in covering large sites quickly and with high resolution. However, it has its limitations in terms of the ability to detect archaeological structures which create only weak magnetic field variations. Its use therefore runs the risk of not obtaining as much information as with a total field magnetometer, such as the G858. The latter, on the other hand, requires much more time to prospect with the same resolution. Using a system with four or more caesium sensors seems to be the best solution to avoid having to choose a compromise between quality, speed and spatial resolution. 


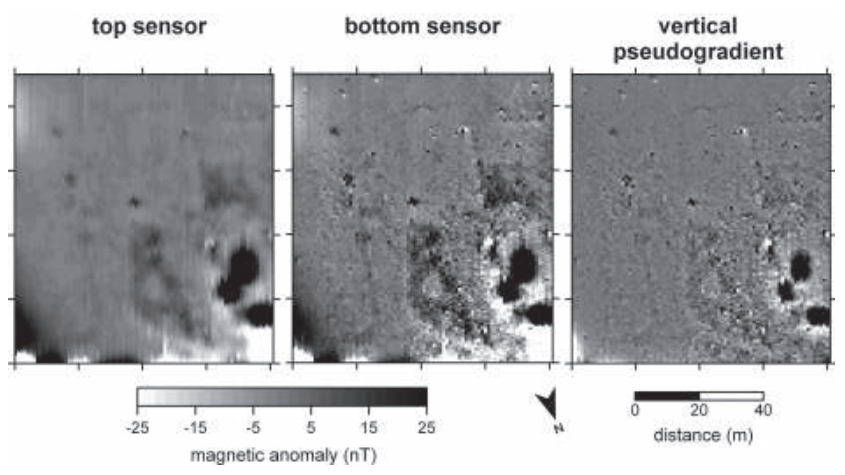

Figure 3: Magnetic survey of a brick-production site near a medieval abbey. Spatial resolution of each map is 7 measurements per $\mathrm{m}^{2}$. These results are obtained after removal of the median of each profile and pole reduction. The pseudogradient shows only three ovens, while the variations of the total field (top and bottom sensors) exhibit associated structures to the south and east of the ovens.

\section{References}

Linford, N., Linford, P., Martin, L. and Payne, A., 2007. Recent results from the English Heritage caesium magnetometer system in comparison with recent fluxgate gradiometers. Archaeological Prospection, 14 (3): 151-166.

Mathé, V. and LÉVÊQue, F., 2003. High resolution magnetic survey for soil monitoring: detection of drainage and soil tillage effects. Earth and Planetary Science Letters, 212: 241-251.

Mathé, V., Lévêque, F., Mathé, P.-E., Chevallier, C. and Pons, Y., 2006. Soil anomaly mapping using a caesium magnetometer: limits in the low magnetic amplitude case. Journal of Applied Geophysics, 58 (3): 202-217. 